\title{
The Role of Public Broadcasting in Media Bias: Do People React Differently to Pro-government Bias in Public and Private Media?
}

\author{
Taka-aki Asano $^{1}$ (D) Atsushi Tago ${ }^{2} \cdot$ Seiki Tanaka $^{3}$ D
}

Accepted: 18 October 2021

(c) The Author(s) 2021

\begin{abstract}
People often reject new information, especially when it does not fit their prior beliefs. But do publics in advanced democracies reject information from public and private media outlets in the same way? We examine this question in the form of the media's pro-government bias in the under-examined case of Japan. By combining unique textual data with an original survey experiment, we document that (1) people generally tend to reject pro-government biased information that overly praises government actions; but (2) the reasons why people reject the same biased information vary-based on their expectations of neutrality for public media, and on expectations derived from political ideology for private media. Our study suggests that the basis of people's motivated reasoning differs when they evaluate content from public and private media.
\end{abstract}

Keywords Public broadcasting · Biased information · Motivated reasoning · Experiments

Seiki Tanaka

S.Tanaka@rug.nl

Taka-aki Asano

takaaki-asano@g.ecc.u-tokyo.ac.jp

Atsushi Tago

tago@waseda.jp

1 The University of Tokyo, Tokyo, Japan

2 Waseda University, Tokyo, Japan and Peace Research Institute, Oslo, Norway

3 University of Groningen, Groningen, The Netherlands 


\section{Introduction}

Obstinate attitudes are prevalent across societies. People tend to cling to their beliefs, often rejecting new information that does not fit their prior beliefs (e.g., Flynn et al., 2018; Nisbet et al., 2018). ${ }^{1}$ But do people also reject new information when it comes from a perceived neutral, reliable information provider? Even if we are generally distrustful of new information, how we reject such information emanating from private and public media may differ as many citizens in advanced democracies have different expectations of public broadcasters. This paper advances a unified theoretical framework to understand how people reject new information from public and private media, and applies it to the question of pro-government media bias in the under-explored case of Japan.

Even in our era of for-profit media, public broadcasters remain central in providing news in many Western democracies (Benson \& Powers, 2011). Alongside the venerable $\mathrm{BBC}$ in the UK, the list includes France Télévisions in France, SVT in Sweden, ABC in Australia, ARD in Germany, Yle in Finland, KBS in Korea, and NHK (Nippon Hōsō Kyōkai) in Japan. While there are different types of public media (Hallin \& Mancini, 2004) and their relationships with governments vary, with some enjoying de facto independence, ${ }^{2}$ all public broadcasters share a common aim: to provide a public service through neutral, reliable content. For example, the BBC's stated mission is "to act in the public interest, serving all audiences through the provision of impartial, high-quality and distinctive output and services which inform, educate and entertain." ${ }^{3}$ It suggests that public television is for everybody and that citizens can expect impartial news and information. ${ }^{4}$ In contrast, some private media companies are expected to be (relatively) ideologically biased (e.g., Fox News and MSNBC in the U.S.) (see also Gentzkow et al., 2015; Puglisi \& Snyder, 2015). ${ }^{5}$

This paper examines how people reject biased content provided by public and private media. We argue that people are less likely to trust news coverage when there is a large gap between the coverage and their expectations, and that their expectations depend on the type of media. Building on previous studies, we argue that citizens expect private media to confirm their political beliefs. When they see that private media is biased in a way that does not confirm their beliefs, they will more likely reject biased information. But in countries with trusted public broadcasters, people expect public media to be neutral; when they see public media providing biased

\footnotetext{
1 See also Alt et al. (2016) for variation in the effect of new information.

2 See Hanretty (2010) for factors affecting the variation in public media's de facto independence. We will also discuss how the variation in media independence may affect our study below.

3 https://www.bbc.com/aboutthebbc/governance/mission

${ }^{4}$ Worryingly, the public considers public television to be increasingly biased. The recent debate over public broadcasting thus centers on how to maintain "public services" given financial constraints and increased commercialization (Bardoel \& d'Haenens, 2008; Blumler, 1993; Meijer, 2005). See also Gehlbach and Sonin (2014) on endogeneity between state intervention and media bias.

5 Public and market-driven media differ in their news content, their impact on people's knowledge, civic participation and levels of trust (Cushion, 2012). By using survey experiments, we control for variation in media content.
} 
information, they see it as an unacceptable deviation from the neutrality principle and tend to reject biased information.

The literature provides ample evidence of the role of political ideology when individuals evaluate new information. It may thus follow that people likewise evaluate the news content of public media through the lenses of political ideology. But particularly in societies with a trusted public broadcaster, it may be people's expectations of media neutrality rather than their political ideologies that inform their evaluations. It implies that the basis of people's motivated reasoning differs depending on whether they are consuming public or private media.

Media are subject to many different forms of bias including gate-keeping bias (which news is selected), coverage bias (how much attention is devoted to a subject), and statement bias (how news is reported) (D'Alessio \& Allen, 2000). Within this classification, our study contributes to the literature on statement bias. A vast literature has examined and confirmed the effect of statement bias on citizens (Baum \& Gussin, 2008; Clayton et al., 2019; Druckman \& Parkin, 2005; Kobayashi \& Yokoyama, 2018; Levendusky, 2013a, b). Partly due to growing concerns about misinformation and fake news, numerous scholars have studied the conditions under which citizens detect and reject statement bias. Some suggest that individuals judge information bias based on the media source (Baum \& Gussin, 2008; Turner, 2007); others that the content itself is more important in citizens' evaluations of biased information (Clayton et al., 2019). To the best of our knowledge, we still know little about how citizens evaluate statement bias in public media and how it may differ from how they evaluate bias in private media. We argue that the difference between public and private media is crucial as it affects how individuals perceive and evaluate bias. We suggest that due to the expectation of neutrality, citizens will likely evaluate statement bias by public media based on the source, while the same people will likely judge private media's biased content based on their own political beliefs, regardless of the source of information.

To examine the plausibility of this argument, we conducted an original survey in Japan in which we embedded a survey experiment. The under-examined case of Japan is apt for our study as Japan has a public broadcaster that people widely believe is neutral (Krauss, 2000). Yet, it is not far-fetched that the media has a progovernment statement bias in some news content (see "Case Selection" section for detail). ${ }^{6}$ By analyzing unique textual information about Japanese television, we first confirm the plausibility of our key assumption: that people expect public media to be neutral. Following the text analysis, our survey randomly assigns a political vignette (pro-government bias or no bias) to a group of respondents, while randomizing the source of the vignette: (1) public television; (2) right-wing private television; (3) left-wing private television. We do not claim that Japan represents all democracies or that the relationship between NHK and its Japanese audience is typical of the role of the public media in democracies. While our results may reflect a specific context in time and place, this paper provides theoretical foundations and an empirical research strategy for future comparative research in democracies with public media.

\footnotetext{
${ }^{6}$ Other countries have also faced pro-government bias in public media [see, for example, Durante and Knight (2012) for the case of Italy].
} 
Public media in democracies are often seen as providers of hard news (Iyengar et al., 2010; Soroka et al., 2013), with exposure to public broadcasting often positively affecting citizens' level of political knowledge (Fraile \& Iyengar, 2014; Soroka et al., 2013). It may be true that public media including NHK have recently become less neutral, while at the same time, they face increased market competition with private media (Bardoel \& d'Haenens, 2008; Meijer, 2005). However, Soroka et al. (2013, pp. 719-720) analysis of cross-country survey data finds a persistent, shared expectation among the general public in Western democracies that public broadcasters should be neutral and fair on political matters. This suggests that although the nature of public media has been increasingly changing, the expectation of public media's neutrality may still hold in most democratic countries and continue to affect how the general public evaluates public media's news contents.

\section{The Argument}

\section{Trust in Media}

Our theoretical argument builds on the literature examining pro-government media bias. Media in democracies can have a variety of biases; here we focus on statement bias, in particular pro-government statement bias. Statement bias is defined as members of the media interjecting their own opinions into coverage, especially when it is favorably or unfavorably slanted towards particular actors or issues (D'Alessio \& Allen, 2000).

In political coverage, these slants are often based on political ideology, often towards political parties and leaders. Numerous studies have found empirical evidence for such ideological bias. ${ }^{7}$ Larcinese et al. (2011) find evidence of partisan bias in U.S. newspapers' coverage of economic issues, with pro-Democratic newspapers devoting more attention to high unemployment when the president is Republican. Groeling (2008) finds that networks such as ABC, CBS, NBC, and Fox tend to cover presidential approval polls based on their political ideology.

When do people trust biased media content? Generally speaking, political ideology matters here as well, as individual political ideology likely influences trust in (biased or unbiased) media and news content. ${ }^{8}$ In the U.S., Gunther (1992) finds that membership in political parties better predicts trust in media than the demographic variables and individual dispositions suggested by earlier research, while Lee (2010) reports that liberals and Democrats have greater trust in mainstream media outlets. In European countries, Ceron and Memoli (2015) show that reading newspapers biased against the government lowers trust in government, particularly among those

\footnotetext{
7 Such ideological bias in media can be measured by left-right positions in a political system (Groseclose \& Milyo, 2005).

${ }^{8}$ People with high trust in news media often expect media to provide correct information and to fulfill social tasks (van Dalen, 2020). According to van Dalen, media credibility is similar to trust in the media, which refers to one's perception of news content trustworthiness. We use the broader concept of trust as we are interested in both people's evaluations of media content and in media reporting styles.
} 
who are already critical. In fragmented media landscapes where the ideological bias of outlets is well-known, people may interpret coverage based on their prior knowledge of the outlet, even when there is no bias in media reporting (Baum \& Gussin, 2008).

The discussion so far suggests that people tend to value their ideological preferences or prior knowledge about the media outlet, and tend not to trust new information to update their opinions, especially when the new information deviates from their existing beliefs. A growing number of studies have thus focused on the conditions under which individual attitudes towards media or media content can change (e.g., Nyhan \& Reifler, 2010).

\section{How People Process Biased Information from Public and Private Media}

People rely on motivated reasoning when they face confronting information, and generally do not trust content that is incompatible with what they already believe. ${ }^{9}$ The literature then suggests that two factors are particularly important in how people process biased information: (1) individual political beliefs (i.e., political ideology and party affiliation as its proxy) and (2) expectations based on prior knowledge or stereotypes about the media outlet (see also Blom (2021) for trust level in news sources). Although both are important, which people use to reject biased information-prior political beliefs or prior expectations about media sources-depends, we argue, on the source of information: public or private media.

When we examine citizens' trust in the media, understanding their expectations of what kinds of bias media should or should not have is crucial. For private media, political ideology often informs people's expectations about (biased) information. For instance, those who espouse left-wing views may think that all private TV stations - whether right or left- do not need to be neutral but should have more leftleaning coverage. It is perhaps for this reason that left-leaning audiences tend not to watch right-leaning programs, and vice-versa (Iyengar \& Hahn, 2009). We thus expect that when citizens detect deviation from their own political ideology, they are more likely to reject the coverage in private media, regardless of the expected ideological predispositions of the media outlet. ${ }^{10}$

For public broadcasters, we argue that their expected role grows in importance as people evaluate coverage. Citizens in many advanced democracies are socialized to believe that public broadcasting should provide balanced, politically unbiased coverage (see the "Case Selection" section for which countries may more strongly

\footnotetext{
9 See Lodge and Taber $(2000,2013)$ for a discussion on motivated reasoning. While people are motivated to be accurate, they are also motivated to protect one's existing beliefs and identities. Lodge and Taber call the former as accuracy goals and the latter as partisan goals. We focus on motivated reasoning based on partisan goals. Motivated reasoning often leads people to reject information that contradicts their preferences (Taber \& Lodge, 2006).

10 People have a harder time recognizing bias that is more consistent with their ideological preferences. Perceived deviation from their expectations may thus matter more than actual bias when people decide whether to trust media.
} 
embrace the neutrality principle). ${ }^{11}$ Soroka et al. (2013)'s cross-national survey confirms that general publics expect public broadcasters to be neutral on political matters. $^{12}$

Public media coverage thus involves a public goods aspect-it is for everyone and should not exclude any points of view, including those of minority groups and people opposed to the government. We argue that this normative idea differentiates public from private media. Accordingly, especially in countries where this normative idea prevails, the expectation of neutrality (rather than one's political beliefs) should grow in importance when viewers evaluate whether they trust public media coverage. If viewers notice a deviation from the public broadcaster's expected role, they tend not to trust the biased information. ${ }^{13}$

Based on this discussion, we advance two general propositions that will help us derive observable implications. First, for public media, we expect:

Proposition 1 People are less likely to trust biased information from public broadcasters as they have higher expectations of neutrality.

This proposition suggests that expected media neutrality may depend not only on citizens but also on macro contexts, leading to cross-country variation in expectations of neutrality. Among these macro contexts, media independence may affect public perceptions of neutrality. If public media in a given country is not (or is not perceived to be) independent, the public may be less likely to think that public media would or should be neutral and Proposition 1 may not hold.

By contrast, consonant to the findings of previous studies, we expect people will judge private media coverage-without expectations of neutrality-based on their ideology, thus rejecting biased information that contradicts their own political beliefs. Hence:

Proposition 2 People are less likely to trust biased information from private media when it is further away from their own political beliefs.

While previous studies have examined variations of Proposition 2, we believe it is important to include the proposition in our theoretical framework. Both Propositions

\footnotetext{
11 We follow D'Alessio and Allen (2000) and posit that media is neutral when media events, on average, contain equal numbers of statements biased in either direction or contain no overtly biased statements. The distinction between unbiased and balanced coverage may be important and requires further research.

12 Ofcom, the UK's communications regulator, reports that British people still trust the BBC as they have watched the public broadcaster for a long time and have confidence in it delivering accurate and trusted news (https://www.ofcom.org.uk/data/assets/pdf_file/0025/173734/bbc-news-review.pdf).

13 People may expect media to cover an issue from a certain perspective, and researchers can examine their reactions when such expectations are realized or violated. In this article, we focus more on normative expectations (Tandoc \& Duffy, 2016), of people thinking that media should cover an issue from a certain perspective. In theory, normative expectations can swing free of evidence and reality. But in practice, normative expectations and reality often go hand in hand. If the public broadcaster in a given society generally reports the news in an unbiased way, citizens will more likely think that the public broadcaster should be neutral.
} 
1 and 2 come from the unified framework, and for our argument to be plausible, we need to find evidence consistent with both propositions, not just with Proposition 1. Empirical support for Proposition 2 consistent with previous studies would also indicate that our analyses are less subject to the idiosyncrasies of our specific case. With these general propositions in mind, we now derive case-specific hypotheses. ${ }^{14}$

\section{Hypotheses for the Case of Japan}

The case of Japan offers an opportunity to systematically assess how the expectation of public media neutrality influences people's evaluations of pro-government statement bias. Still, we note two important caveats regarding the case. First, because the current ruling party in Japan is right-wing, our study focuses on right-wing statement bias in favor of the right-wing government. Second, there may be an important distinction between bias towards leaders and political parties. But because Japan has a parliamentary system, it is difficult to distinguish bias towards a political leader, in particular the Prime Minister, from his or her political party (and also the government). With these caveats in mind, we summarize our case-specific hypotheses.

\section{Expectations Regarding Public Media}

Since the end of World War II, Japanese media have rarely given full-throated approval to the government (Sugawara, 2016). Although critics have more recently charged cozy relations between certain media outlets and the Liberal Democratic Party (LDP) administration (Fackler, 2016; Suzuki, 2015), Japanese citizens generally do not expect TV stations to embrace pro-government bias and are less likely to trust overtly biased information as it goes against their expectations.

We nevertheless argue that there is heterogeneity in the impact of broadcasters' pro-government bias, and that the reasons for citizens to reject pro-government bias differ depending on the type of media. In Japan, there is widespread belief that public media (i.e., NHK) should offer politically neutral coverage and be independent of government positions; NHK is known to provide "safe" news. To maintain its neutrality, NHK is financed through a citizens' fee called "Jushin-ryo", although its president and reporting committee members must be nominated and approved by the government. $^{15}$

Our observational study confirms the existence of the neutrality principle and we find that compared to private TV stations, NHK tends to cover issues from diverse perspectives rather than from a single biased perspective, generally reporting facts without excessive editorial. If the assumption of neutrality is reasonable, Japanese citizens exposed to pro-government bias from NHK may consider it an unacceptable deviation, leaving them less likely to trust the biased information. The degree of distrust should also be stronger among those who believe in NHK's neutrality. This yields our first testable hypothesis, based on Proposition 1:

\footnotetext{
14 See Online Table A.1 for a summary of our theoretical expectations.

15 Like BBC, NHK is legally bound to be neutral by the Broadcast Law (Krauss, 1998).
} 
Hypothesis 1.1 Japanese people are less likely to trust NHK's pro-government bias, with the degree of distrust larger among those who believe in NHK's neutrality.

This empirical implication-as previous studies have found (Baum \& Gussin, 2008) - is that individual expectations of media sources matter. But our discussion indicates that prior political attitudes (i.e., ideological preference and party affiliation) also inform people's evaluations of biased statements (Clayton et al., 2019), resulting in interesting cross-cutting preferences when people have contradictory expectations. While people may expect public media to be neutral, some of the same people may strongly support the incumbent government. When the public broadcaster disseminates pro-government information, they face a dilemma: they disagree with the pro-government bias due to their expectation of neutrality, but appreciate the content due to their political beliefs. Which of these considerations take precedence is ultimately an empirical question. But in light of Proposition 1, we expect the following to be true in Japan, where the expectation of public media neutrality remains strong:

Hypothesis 1.2 Among those who believe that NHK should be neutral, even supporters of the incumbent government and right-wing voters (ideologically close to the government) do not trust NHK's pro-government bias as much as people who are non-supporters of the government and/or left-wing voters.

This working hypothesis serves as a robustness check for Hypothesis 1 by examining the extent of the effect of people's belief in public media neutrality, and whether expectations of neutrality are undermined by political ideology. Given the vast literature emphasizing the importance of social identity and political affiliation (Achen \& Bartels, 2016; Levendusky, 2013a), the importance of ideological and political preferences may potentially outweigh citizens' prior expectations of media even in Japan, which would delineate the boundary of our argument.

\section{Expectations Regarding Private Media}

In addition to NHK, Japan has a variety of private media companies, allowing us to examine the effect of expected neutrality on how people process biased information and the plausibility of Proposition 2. In theory, Japanese left-leaning private media is considered more critical of the hawkish government, while right-leaning media is, on average, more consistent with the government's positions. For example, Yomiuri Shimbun, a right-leaning newspaper, supported former Prime Minister Abe's bills that allow Japan's Self Defense Forces (the de facto military) to exercise the right of collective self-defense and deploy troops overseas. Asahi Shimbun, a left-leaning newspaper, opposed these bills (Yamada \& Kim, 2016). Still, without the expectation of neutrality, we expect people will evaluate media content primarily based on their political beliefs, regardless of their prior expectations about private media. Because left-leaning individuals are generally more critical of hawkish governments, they should be less likely to trust information biased in favor of the government. In 
contrast, right-leaning individuals may be more likely to trust the biased information because it fits their ideology. This leads to our final testable hypothesis:

Hypothesis 2 Those who think their ideological position is to the left are less likely to trust pro-government information from private media than those who think their ideological position is to the right.

\section{Research Design}

\section{Case Selection}

Before explaining our case selection, we note that this paper mainly considers television programs. Most citizens' political knowledge comes from what they learn via the media (Iyengar, 1991). Although online social media is growing in importance, recent findings show that the influence of television can spread far beyond conventional viewers through inter-personal discussions based on media coverage (Druckman et al., 2017). Although the number of Japanese people who consume news through portal sites and social media is growing, most still rely on TV for hard news like political news (Taniguchi, 2015). Our survey (see the "Survey Design" section) shows that about $60 \%$ of respondents said they watch news on TV every day, while only $8 \%$ did not watch TV at all in the past week.

Given our theoretical expectations, an ideal case would fulfil the following three conditions: (1) the existence of a public television broadcaster; (2) a widely-held belief that the public provider is neutral; and (3) the possibility that public and private media may be seen to bias information in favor of the government (as our experimental vignette cannot be seen as unrealistic, see below). While many countries fulfil these conditions, there has been a paucity of research in Japan-a valuable case study for comparative political communication research. While the second condition is the most important and will be examined in greater detail below, concerns have been voiced about the Japanese government's direct and indirect interference in media communications, bearing on the third condition. It is thus plausible that both public and private media overtly support the government in their news content. ${ }^{16}$

We now elaborate on our key assumption that the Japanese public widely expects NHK to be neutral. The remainder of this section examines the empirical foundations of this assumption. NHK states that its mission is to provide a public forum that unites people by offering accurate information, indicating that citizens may expect accurate, non-biased news from NHK. Our study relies on the assumption that NHK is considered a neutral, reliable news provider. To validate this assumption, we first collected unique textual data on Japanese television programs between 2001 and 2015, via M Data (http://mdata.tv/en/), a Japanese company that transforms visual information from television programs into textual data. Our data cover all programs aired by NHK (both general and educational programs) and by five

\footnotetext{
${ }^{16}$ See, for example, the report by the UN Special Rapporteur on Freedom of Expression, May 31, 2017 (http://hrn.or.jp/eng/news/2017/05/31/david-kaye-report/).
} 
major private television stations: Nippon TV (NTV), Asahi TV (EX), TBS, Fuji TV (CX), and TV Tokyo (TX). We selected a topic that can be discussed from a wide range of left-wing and right-wing perspectives: Japan's past wars. We extracted war-related programs from the M Data database using the following search terms: "sensou" [war], "heiwa" [peace], "shusen" [end of war], and Yasukuni (see Online Appendix A2 for more information about the data). ${ }^{17}$

First, we calculate the proportion of programs containing opinions and editorial by commentators for each TV station (see Online Fig. A.1). We see that NHK programs contain markedly fewer commentator opinions than private news programs, suggesting that NHK focuses more on facts than news based on opinion or ideology.

Second, we analyze how each TV station covers the above topics. We find that NHK covers more topics related to past wars than private TV companies (Online Fig. A.3). NHK reports on 37.9 topics on average each year, while the mean in private news programs is 23.3 . The difference is statistically significant at the $1 \%$ level-indirect evidence of NHK's neutrality principle and its aim to provide more diverse content than private media. Our empirical evidence is also confirmed by other polls. A poll by the Japan Press Research Institute in 2015 found people perceiving NHK to be more neutral than private media, with fairer coverage of World War II and postwar history on the 70th anniversary of the end of the war. ${ }^{18}$

For private media, each private television station in Japan is tied to a major daily newspaper-NTV with Yomiuri Shimbun, Asahi TV (EX) with Asahi Shimbun, TBS with Mainichi Shimbun, Fuji TV with Sankei Shimbun, and TV Tokyo with Nikkei Shimbun. Although there has been less discussion of ideological bias among TV stations, recent studies find that these newspapers have ideological predispositions (Kaneko et al., 2021; Taniguchi, 2018). Most notably, Asahi Shimbun is recognized as left-leaning, and Yomiuri Shimbun as espousing conservative and rightwing views (Taniguchi, 2015). Our analyses use the two private TV stations Asahi TV (EX) and NTV and compare them with the public broadcaster NHK. ${ }^{19}$

Before moving to our survey design and findings, we discuss two factors that may affect the generalizability of our case: media independence and trust in government. First, perceived or actual media independence from the government can affect citizens' evaluations of media content. For instance, if media is not perceived as independent in a given country, its citizens may not trust the news content or consider it neutral. Hanretty (2010) ranked public broadcasting in 36 countries by its degree of independence from the government. According to Hanretty's index, Japan's NHK is as independent as the UK's BBC and Denmark's DR. Hanretty further suggests that, according to available European polling data, perceived independence should be similar to his objective measures. In general, Hanretty (2010)'s analysis shows that

\footnotetext{
17 Yasukuni is a controversial Japanese Shinto shrine dedicated to the war dead. We use it for our survey experiment below.

18 See report by Japan Press Research Institute, October 24, 2015 (https://www.chosakai.gr.jp/wp/wpcontent/themes/shinbun/asset/pdf/project/notification/jpyoronreport08-2015.pdf).

19 The (perceived) ideological predispositions of TV stations (and newspapers) are confirmed by our original survey (see below).
} 
the independence of public media tends to be higher in advanced Western democracies including Japan than countries in Eastern Europe and Latin America.

The level of trust in government may also affect how people evaluate pro-government bias. If trust in the government is high, pro-government bias may not be seen as bias, but as a neutral statement. To explore this possibility, Online Fig. A.4 plots the level of trust in governments and (public and private) broadcasters using the World Values Survey Wave 7 (2017-2020). As the figure shows, Japanese citizens' confidence in their government is in the middle of the world sample. On the other hand, Japanese trust in television is higher than in other developed countries. While higher trust in television stations in Japan may qualify as a scope condition, the figure confirms that Japan is not an outlier regarding trust in government.

\section{Survey Design}

To test our case-specific hypotheses, we conducted a survey in Japan containing a vignette experiment in which we randomized two components: (1) pro-government bias and (2) type of media. Below, we explain how we collected the sample and conducted the experiment.

\section{Survey}

The survey was conducted by Nikkei Research in August 2019 and we collected about 2600 randomly chosen participants from its panel. While it is not a probability sample, key demographic variables such as age, gender, and residential location yield a reasonable approximation of the general population (see Online Appendix A4 for survey details).

We first obtained consent from survey respondents, ensuring they are 18 or older and Japanese citizens. After asking a series of pre-treatment demographic questions including about our heterogeneous treatment effect variables (i.e., respondents' selfreported ideology; initial perceptions of media; party affiliation), we embedded a vignette experiment in the survey (Online Appendix A5 contains the original instrument and its English translation).

\section{Vignette Experiment}

In the experiment, all respondents first received hypothetical basic information presented like television news. We made the scenario hypothetical for several reasons. Most importantly, the media have different ways of covering news (e.g., Cushion, 2012) and it was more feasible to insert hypothetical pro-government statement bias consistent across all private and public media (rather than using actual news stories that likely vary in content). We also needed to use content slanted towards the government but that could not be considered false news, which could generate alternative interpretations for why respondents do not trust the provided news. To avoid such a scenario, by explicitly stating that this is a fictional story, we asked respondents to answer whether they can trust the news assuming that it is actual 
news. Although using a hypothetical scenario may lack the external validity of actual news, we believe our design with the fictional story has the advantage of controlling for media heterogeneity.

Still, as experiments with more realistic scenarios tend to yield more accurate estimates (Incerti, 2020), we constructed the information based on an actual news article about 50 supra-party Diet members visiting Yasukuni shrine (Asahi Shimbun, October 18, 2018), which often results in diplomatic rows between Japan and its neighboring countries. It also included the statement that the Chinese government did not protest the visit, which becomes important in the treatment groups (see below for an example vignette). ${ }^{20}$

After presenting the hypothetical basic scenario to all respondents, they were randomly assigned to one of six conditions. The randomization is based on two sets of cross-cutting treatments (i.e., 3 types of media $\times$ with or without pro-government bias). The treatment groups read the following biased information at the end of the hypothetical scenario: "The [NHK/NTV/EX]'s news commentator praises Prime Minister Abe by saying that the lack of Chinese protest is largely due to Prime Minister Abe's diplomatic efforts." Note that although this may only be a statement from an individual who works for the company, commentators in Japanese media have often held important positions within the company. ${ }^{21}$ Our manipulation check shows that many respondents understood the treatment sentence to include pro-government bias (77\% on average). ${ }^{22}$ Following Aronow et al. (2019), we estimate intent-to-treat effects without using our manipulation check question in our analyses below. ${ }^{23}$ The control groups did not receive the biased information in which a news commentator praises Prime Minister Abe.

Table A.2 in the Online Appendix summarizes the six treatment groups. ${ }^{24} \mathrm{We}$ have three control groups (Groups 1, 3, and 5 serve as a control group for Groups 2, 4, and 6, respectively). Because the control groups mention a media source (e.g., "According to NHK, ..."), we can isolate the effects of pro-government bias for each media outlet. NHK represents public media (Groups 1 and 2), TV Asahi (EX) a leftleaning outlet (Groups 3 and 4), and NTV a right-leaning outlet (Groups 5 and 6).

\footnotetext{
${ }^{20}$ While some people may have wondered whether this is truthful, the effect should be controlled for, as this information is included in both the treatment and control groups.

21 For example, Shuntaro Torigoe, correspondent and editor-in-chief of the Sunday Mainichi at the Mainichi Shimbun, became a commentator on Super Morning (TV Asahi, 1993-2011). Editors-in-chief and company presidents often have outsized influence over the news reported by Japanese TV stations (Kabashima et al., 2010), suggesting the importance of statements made by individual commentators.

22 We also conducted a pre-test to ensure that respondents understood our manipulation.

23 We still use manipulation checks to ensure sample quality (see Aronow et al., 2019; Kane \& Barabas, 2019, for discussion on the utility of manipulation checks). We provide robustness checks in Online Tables A.9, A.10 and A.11. The results are largely similar and do not affect our main findings.

24 We did not include another possible treatment about an "anti-government bias," although this is theoretically interesting for future research.
} 
The example below is the vignette used in the treatment group of NHK with progovernment bias (i.e., Group 2). ${ }^{25}$

Please read the following fictional news report by NHK and answer the following questions.

According to NHK, about 50 lower and upper house Diet members who belong to the all-party parliamentary group called "Diet member group for visiting Yasukuni shrine" visited Yasukuni Shrine in Kudan-kita in Tokyo on August 15, when Japan commemorates the anniversary of the end of World War II. Since the second Abe administration, the Prime Minister has not visited the shrine, but many Diet members go to the shrine on occasions like this kind of spring/fall festival. There was no protest by the Chinese government on this particular visit. The NHK's news commentator praises Prime Minister Abe by saying that the lack of Chinese protest is largely due to Prime Minister Abe's diplomatic efforts.

We collected two trust-related variables for our dependent variables. The first measures whether respondents trust the information (i.e., information with or without the pro-government bias) based on the question "Do you trust the news report?" The second indicates whether respondents trust NHK, left-leaning, and right-leaning media, respectively. This paper focuses on the first dependent variable; the results for the second variable are reported in the Online Appendix.

There are at least two potential interpretations of our first trust measure: (1) respondents think that a news report is likely to come from a particular media outlet; and (2) they think that a news report is trustworthy. Our intention is to examine the second interpretation, but in combination with a part of the first interpretation. More specifically, we investigate whether respondents think a news item is trustworthy (the second interpretation) and whether this trust varies depending on the media outlet. Although our wording tries to eliminate the unconfounded version of the first interpretation, it remains possible that some respondents may have the first interpretation in mind. Future research should differentiate these more clearly.

By comparing the treatment groups (i.e., "with or without pro-government bias" and "NHK or private media"), we examine how an expected norm-public broadcasters should be neutral — affects the level of trust in the news, while controlling for other factors. To examine the treatment effect, we first conduct a t-test (Table 1b). Then, as our main hypotheses involve non-experimental variables (e.g., perceived media neutrality), we perform ordinary least square regression analyses with a set of common covariates to increase precision: respondents' gender, age, education, political interests, frequency of television viewing, and credibility of the assigned broadcaster. Online Appendix A3 provides summary statistics for key demographic variables to ensure that randomization was successful and covariates among different treatment groups are well balanced. ${ }^{26}$

\footnotetext{
25 Some respondents may be daily exposed to similar actual statements, which may confound our estimates. But randomized treatments should control for the level of daily exposure. Should the exposure problem remain, it would only lead to under-estimating our treatment effect.

26 The survey design was pre-registered at the Open Science Framework (OSF).
} 


\section{Findings}

First, by using our original survey, we confirm whether our assumption about the NHK's neutrality principle is plausible. Figure 1 reports the mean perceived ideological positions of the three TV stations, where respondents were asked to rate them on a scale from 0 (the most left) to 10 (the most right). The figure confirms our observational analysis and assumption, with respondents seeing NHK as more neutral than the two private outlets. The ideological position of TV Asahi (EX) is considered to be left, while NTV is perceived as somewhat right-leaning, though not far from NHK. ${ }^{27}$ The figure also indicates respondents' own ideological positions; the average ideological position of the sample is located somewhere in-between NHK and NTV.

Table 1a shows the mean and standard deviation of answers to the question: "Do you agree that [NHK/EX/NTV] should be more neutral than other TV stations? Or do you disagree with this statement?"28 The table shows that Japanese people expect neutrality from NHK but not from private media. This initial exploration confirms that our assumption is plausible. ${ }^{29}$

Table $1 \mathrm{~b}$ reports average levels of distrust towards the assigned information among treatment groups. The p-values indicate the results of t-tests for differences in means between the control and treatment groups for each TV station. Each participant answers their trust level for the assigned information on a 5-point scale, with higher values meaning higher distrust. The table shows that for all three TV stations, respondents, on average, tend to distrust pro-government bias. This is consistent with our baseline expectation that Japanese citizens are less likely to trust progovernment bias, potentially because it runs against their prior expectations about media reporting. ${ }^{30}$ Despite only a short sentence praising the government, respondents, on average, clearly show aversion to pro-government bias and tend to distrust information that overly praises the government's actions. ${ }^{31}$

However, we find that the reasons for rejecting pro-government bias depend on which media outlet reports the biased news, revealing that the type of media-public or private-seems to prompt different expectations in evaluating media content. To test our first hypothesis that those who believe in public media's neutrality tend

\footnotetext{
27 The difference between NHK and NTV is statistically significant.

28 We use this measure as our moderator variable. It is measured in comparison to other TV stations and may differ from an alternative neutrality measure in absolute terms. For all the moderation analyses below, we interact a moderator with our treatment variable: $Y=\alpha+\beta_{1}$ Moderator $+\beta_{2}$ Treatment $+\beta_{3}$ Moderator $\times$ Treatment .

29 Consistent with our argument, the expectation of neutrality from NHK is not correlated with respondents' ideological positions. The correlation coefficient between the two variables is 0.01 ( $\mathrm{p}$-value $=0.75$ ).

30 There is a potential multiple comparison problem in conducting significance tests. We thus also use Bonferroni p-value adjustment to correct false discovery rates. Results largely remain similar.

31 It is possible that some respondents thought our treatment is weak and/or the pro-government statement we inserted is true-that Abe really did well in diplomacy. If this were the case, we would expect respondents in the treatment groups to be less likely to reject the coverage, or no statistically significant difference between the control and treatment groups. Together with our manipulation check, it is reasonable to say that most respondents detected bias in the coverage (focusing on the term "praise").
} 


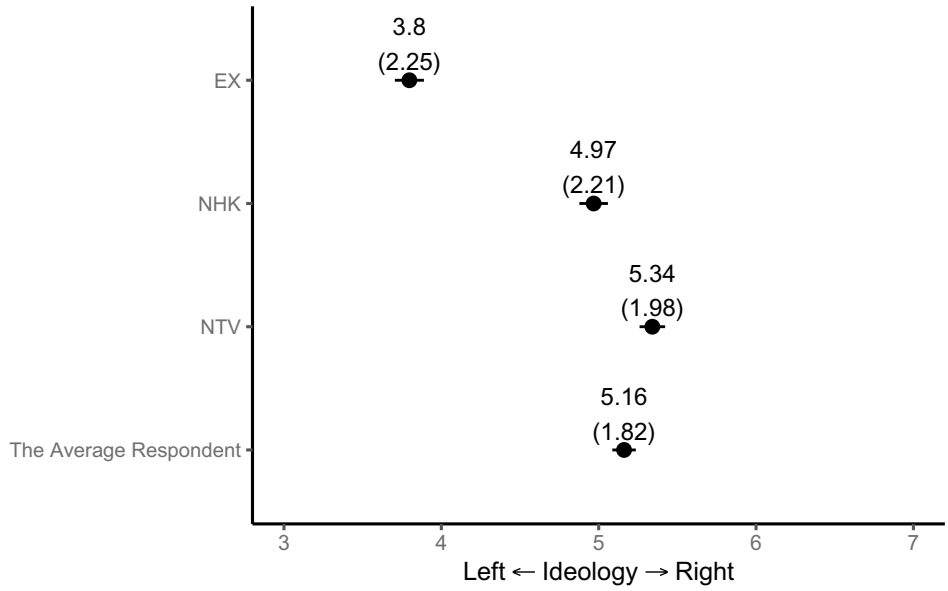

Note: Whiskers indicate $95 \%$ CI; Standard deviation in parentheses

Fig. 1 Mean perceived ideological positions of TV

Table 1 Respondent's views on the assigned TV station, by the pro-government bias treatment

\begin{tabular}{lllc}
\hline & Control & Pro-government bias & p-value \\
\hline $\begin{array}{l}\text { (a) Do you agree that [NHK/EX/NTV] should } \\
\text { be more neutral than other TV stations? }\end{array}$ & & & \\
EX & $3.16(1.17)$ & $3.08(1.14)$ & 0.3 \\
NHK & $1.95(1.07)$ & $1.99(1.16)$ & 0.6 \\
NTV & $2.98(0.86)$ & $3.07(0.98)$ & 0.2 \\
(b) Do you trust the news report? & & & \\
EX & $3.05(1.00)$ & $3.80(1.01)$ & $<0.001$ \\
NHK & $2.97(1.03)$ & $3.54(1.06)$ & $<0.001$ \\
NTV & $2.91(0.99)$ & $3.48(1.07)$ & $<0.001$ \\
\hline
\end{tabular}

We provide mean values and standard deviation in parentheses. t-test is used for statistical tests. The scale ranges from 1 (Yes) to 5 (No)

to distrust pro-government biased information more, we interact the pro-government bias treatment with respondents' expected neutrality for the TV station. We find that the heterogeneous treatment effect of NHK indeed differs from private television, with the level of distrust depending on individuals' prior expectations of neutrality. Figure $2 \mathrm{a}$ shows that the interaction term Pro-government bias $\times$ Neutrality is statistically significant at the $5 \%$ level only in the case of NHK. Figure $2 \mathrm{~b}$ visualizes the finding that the more respondents expect neutrality from NHK, the more they distrust the information including pro-government bias (see Online Table A.5 for full results). Our analysis supports Hypothesis 1.1.

We expected that people's political beliefs would affect the importance of the expected neutrality principle (Hypothesis 1.2). Here we consider two proxies for 
political beliefs: respondents' ideology and party affiliation. Figure 3 reports the results (see Online Table A.6 for full results). The left panel uses the interaction of Pro-government bias $\times$ Respondent's Ideology; the right panel uses Pro-government bias $\times$ LDP Supporters. Both panels use samples of respondents who believe NHK should be neutral. The figure indicates that both variables are not statistically significant at the 5\% level, suggesting that respondents' political beliefs do not affect the rejection of biased information in public media. ${ }^{32}$ But in terms of the main effect of the pro-government bias variable, we only find statistically significant results with the model using the party affiliation variable (the right panel)_regardless of party affiliation, those who expect NHK to be neutral tend to distrust pro-government biased information, while the pro-government bias variable fails to reach a statistically significant level for the model with the respondents' ideology variable. This suggests that although people often evaluate public media content based on their expectation of neutrality, political ideology may also be important for some individuals. ${ }^{33}$

For private media, we expected that respondents' ideology would be most important in evaluating information (Hypothesis 2). We use Pro-government bias $\times$ Respondent's Ideology for the analysis and find that regardless of the private TV station, respondents' ideology influences how they judge pro-government bias (main and interaction results are reported in the top panel). Figure 4 (the bottom panels) clearly shows that left-leaning individuals are more likely to reject private media's pro-government bias than right-leaning individuals (see Online Table A.7 for full results). ${ }^{34}$ This is consistent with Hypothesis $2 .{ }^{35}$

Overall, we find robust evidence for Hypotheses 1.1 and 2 that people reject media content when they detect deviation from their expectations, which are informed by whether the media outlet in question is public or private. For public media, people tend to expect neutrality; for private media, people tend to rely on their political ideology to judge media content. We find only partial support for Hypothesis 1.2, which suggests that the expectation of neutrality from public media varies between individuals. A final caveat is that these findings hold only for levels of trust in the provided information. We do not find statistically significant results for overall trust in media, suggesting that Japanese citizens have stable preferences and that a single piece of information, unsurprisingly, does not change their trust in media more generally. ${ }^{36}$

\footnotetext{
32 Because the null finding may be due to small sample size, we also conduct bootstrapping but find similar results. Online Fig. A.5 replicates Fig. 3 with the bootstrap samples (rep. $=2000$ ).

33 Online Table A.6 also shows the results for those who do not expect NHK to follow the neutrality principle. Among this group, LDP supporters and right-leaning citizens may be more likely to trust reports with pro-government bias. Although the direction of the coefficients is as expected, we cannot find a statistically significant result at the $5 \%$ level, in part due to the small sample size.

34 Some respondents may have thought that pro-government bias violates Japan's broadcasting law, thus rejecting the information from this legal standpoint. Although it is unlikely and cannot explain the heterogeneous effects of expecting neutrality and political ideology, it remains possible and should be researched further.

35 Even when trust in the Abe administration is included in the model, the moderating effect of respondents' ideology remains similar.

36 Online Table A. 8 reports the finding.
} 


\section{(a) Coefficients}

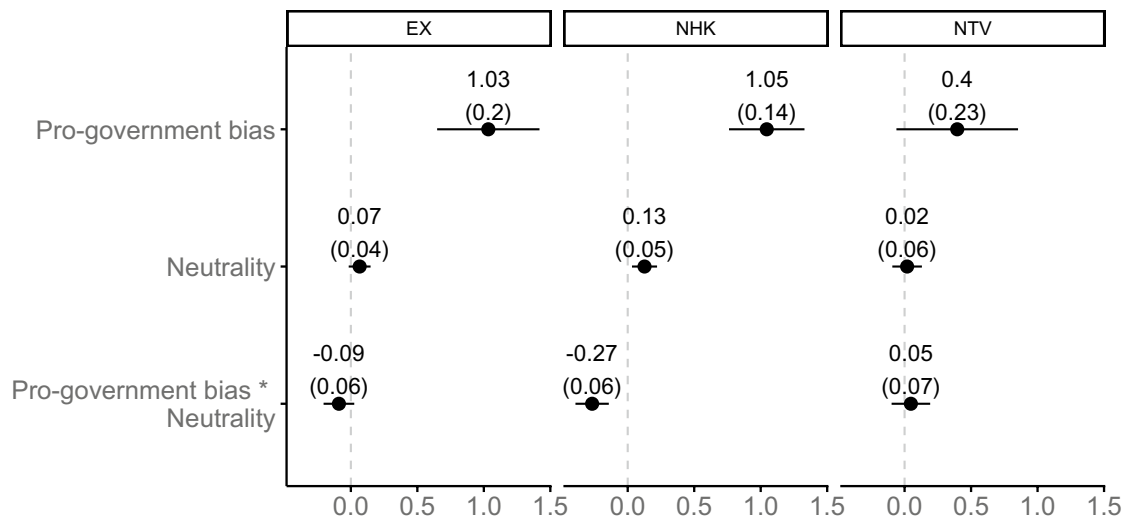

(b) Marginal Effects: NHK

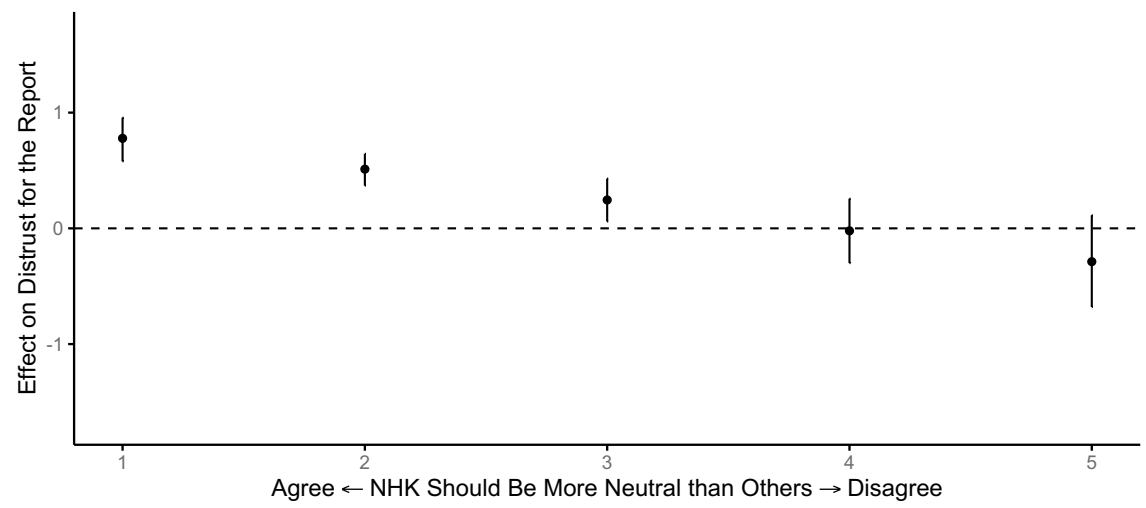

Fig. 2 Moderation effect of respondents' views on the neutrality of the assigned TV station on distrust in provided information

(a) Respondents' Ideology

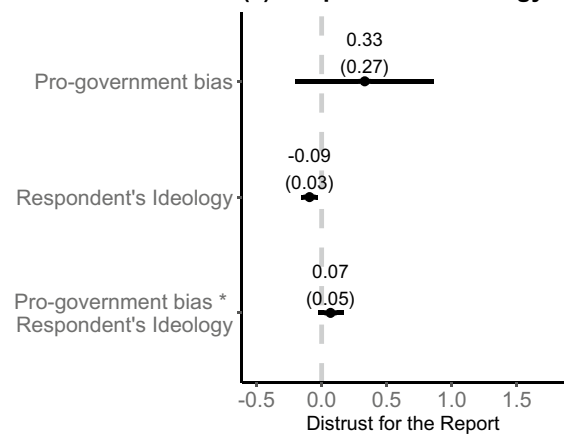

(b) Party Affiliation

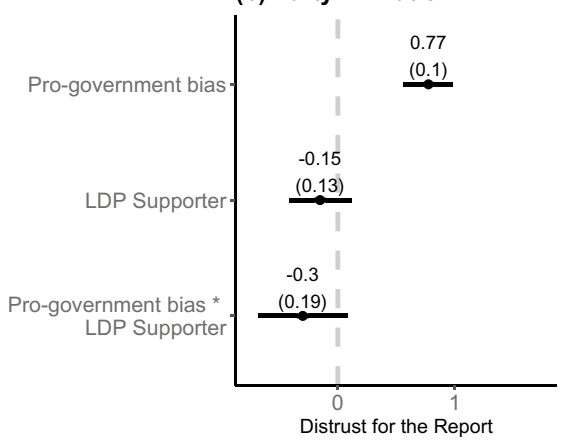

Note: Whiskers indicate $95 \%$ CI; Standard error in parentheses

Fig. 3 Moderation effect of respondents' ideology or party affiliation on distrust in provided information, for those who believe NHK should be neutral 


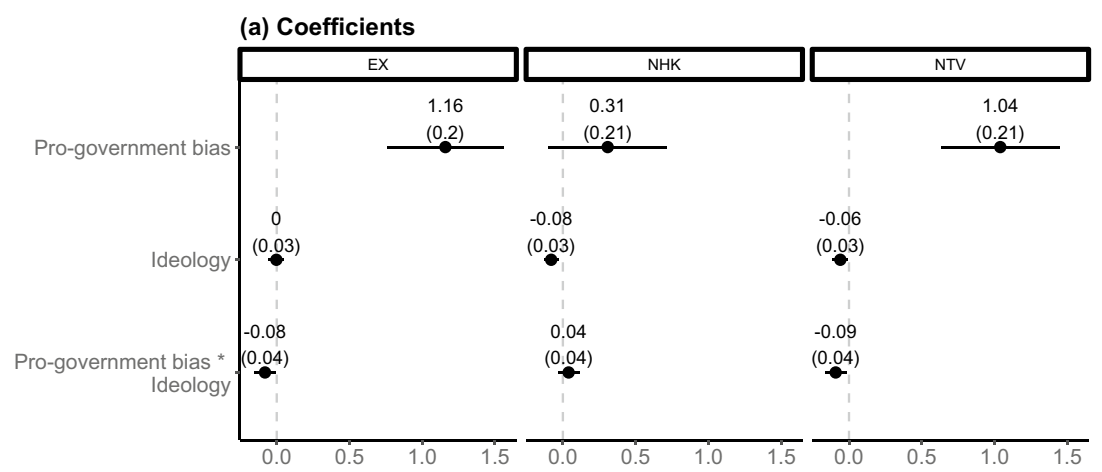

(b) Marginal Effects: EX

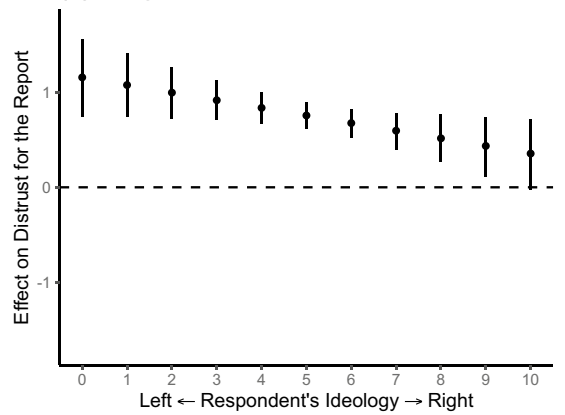

(c) Marginal Effects: NTV

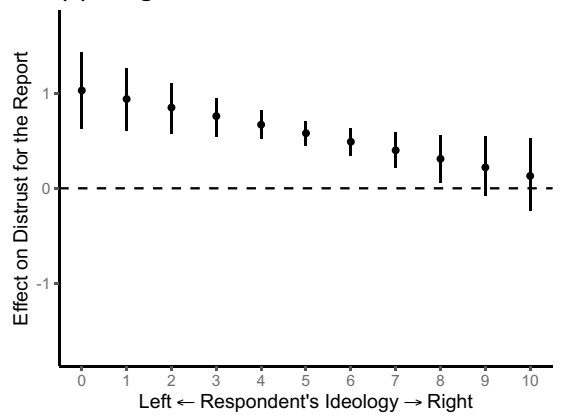

Note: Whiskers indicate $95 \% \mathrm{CI}$; Standard error in parentheses

Fig. 4 Moderation effect of respondents' ideology on distrust in provided information

\section{Conclusion}

This paper argued that how people react to pro-government bias may differ depending on the type of media, with people evaluating public media content based on expected neutrality and private media content based on political ideology. Our survey experiment in Japan provided consistent support for the main argument. As in previous studies, we found that people rely on their prior political beliefs when they reject pro-government bias in private media. The pro-government bias of public media, however, was judged based on people's expectations of neutrality rather than their prior political beliefs. The expectation of neutrality was so strong that it could outweigh the impact of prior political beliefs (at least for party affiliation), suggesting that the basis of people's motivated reasoning may differ when they evaluate content from public media, particularly in societies where citizens widely expect it to be neutral.

We believe that our findings are relevant to other democracies where public media plays a central role. Many studies of public broadcasting point to the growing difficulty of maintaining the neutrality principle and increased bias in public media (Bardoel \& d'Haenens, 2008; Blumler, 1993; Meijer, 2005). This trend notwithstanding, 
our study shows that many citizens in democracies still expect public media to be neutral-an expectation that affects how they evaluate public media content.

We are aware that our study does not offer a comprehensive test of the impact of biased information provided by public and private media. Our single case study inevitably has limitations; a comparative study covering more issues and countries would thus be needed to obtain a more accurate conclusion. Still, we believe this paper provides the theoretical foundations and an effective research design for such comparative research.

Fake news including misinformation and dis-information (false information purposely spread to deceive people) are engulfing Western democracies (Lazer et al., 2018). With the Internet and social media, the impact of fake news is growing worldwide (Vosoughi et al., 2018). We believe it is within this context that public broadcasting can still play an important role as a neutral, reliable provider of information in advanced democracies in the twenty-first century. Ultimately, one of our main messages is that democratic citizens still expect public broadcasting to be neutral and this expectation affects how they evaluate public media content, which may in turn continue to incentivize public media and governments to provide reliable, unbiased information.

Supplementary Information The online version contains supplementary material available at https://oi. org/10.1007/s11109-021-09756-0.

Acknowledgements We would like to thank Kazunori Inamasu, Steve Pickering, Eike Rinke, Masaki Taniguchi, Shoko Omori, and three anonymous reviewers for their valuable suggestions and feedback. Meindert Boersma offered excellent research assistance for the project. The project is funded by the Grant-in-Aid for Scientific Research (Grant No. 17H00973 and 17H02628) of Japan's Ministry of Education, Culture, Sports, Science and Technology. The human subject protocol of the research was evaluated and approved by ethics committees at Waseda University. We also registered our survey experiment design at Evidence in Governance and Politics (EGAP, ID: 20190815AA). Full replication materials are available at the Harvard Dataverse (https://doi.org/10.7910/DVN/R57MJ4). The authors are listed in alphabetical order, implying equal authorship.

Funding Funding was provided by Japan Society for the Promotion of Science (JP) (Grant Nos. 17H00973 and 17H02628).

Open Access This article is licensed under a Creative Commons Attribution 4.0 International License, which permits use, sharing, adaptation, distribution and reproduction in any medium or format, as long as you give appropriate credit to the original author(s) and the source, provide a link to the Creative Commons licence, and indicate if changes were made. The images or other third party material in this article are included in the article's Creative Commons licence, unless indicated otherwise in a credit line to the material. If material is not included in the article's Creative Commons licence and your intended use is not permitted by statutory regulation or exceeds the permitted use, you will need to obtain permission directly from the copyright holder. To view a copy of this licence, visit http://creativecommons.org/licen ses/by/4.0/.

\section{References}

Achen, C. H., \& Bartels, L. M. (2016). Democracy for realists: Why elections do not produce responsive government. Princeton: Princeton University Press. 
Alt, J. E., Lassen, D. D., \& Marshall, J. (2016). Credible sources and sophisticated voters: When does new information induce economic voting? Journal of Politics, 78(2), 327-342.

Aronow, P. M., Baron, J., \& Pinson, L. (2019). A note on dropping experimental subjects who fail a manipulation check. Political Analysis, 4(27), 572-589.

Bardoel, J., \& Haenens, L. (2008). Reinventing public service broadcasting in Europe: Prospects, promises and problems. Media, Culture \& Society, 3(30), 337-355.

Baum, M. A., \& Gussin, P. (2008). In the eye of the beholder: How information shortcuts shape individual perceptions of bias in the media. Quarterly Journal of Political Science, 3(1), 1-31.

Benson, R., \& Powers, M. (2011). Public media and political independence: Lessons for the future of journalism from around the world. Washington, DC: Free Press.

Blom, R. (2021). Believing false political headlines and discrediting truthful political headlines: The interaction between news source trust and news content expectancy. Journalism: Theory, Practice \& Criticism, 22(3), 821-837.

Blumler, J. G. (1993). Meshing money with mission: Purity versus pragmatism in public broadcasting. European Journal of Communication, 4(84), 403-424.

Ceron, A., \& Memoli, V. (2015). Trust in government and media slant: A cross-sectional analysis of media effects in twenty-seven European countries. International Journal of Press/Politics, 20(3), 339-359.

Clayton, K., Davis, J., Hinckley, K., \& Horiuchi, Y. (2019). Partisan motivated reasoning and misinformation in the media: Is news from ideologically uncongenial sources more suspicious? Japanese Journal of Political Science, 20(3), 129-142.

Cushion, S. (2012). The democratic value of news: Why public service media matter. Basingstoke: Palgrave Macmillan.

DAlessio, D., \& Allen, M. (2000). Media bias in presidential elections: A meta-analysis. Journal of Communication, 50(4), 133-156.

Druckman, J. N., Levendusky, M. S., \& McLain, A. (2017). No need to watch: How the effects of partisan media can spread via interpersonal discussions. American Journal of Political Science, 62(1), 99-112.

Druckman, J. N., \& Parkin, M. (2005). The impact of media bias: How editorial slant affects voters. Journal of Politics, 67(4), 1030-1049.

Durante, R., \& Knight, B. (2012). Partisan control, media bias, and viewer responses: Evidence from Berlusconi's Italy. Journal of the European Economic Association, 10(3), 451-81.

Fackler, M. (2016). Taming the watchdogs: Political pressure and media self-censorship in Abe's Japan [Abe Seiken ni Hirefusu Nihon no Media]. Tokyo: Futabasha.

Flynn, D., Nyhan, B., \& Reifler, J. (2018). The nature and origins of misperceptions: Understanding false and unsupported beliefs about politics. Advances in Political Psychology, 38(1), 127-150.

Fraile, M., \& Iyengar, S. (2014). Not all news sources are equally informative: A cross-national analysis of political knowledge in Europe. International Journal of Press/Politics, 19(3), 275-294.

Gehlbach, S., \& Sonin, K. (2014). Government control of the media. Journal of Public Economics, $118(1), 163-171$.

Gentzkow, M., Shapiro, J. M., \& Stone, D. F. (2015). Media bias in the marketplace: Theory. In S. P. Anderson, J. Waldfogel, \& D. Strömberg (Eds.), Handbook of media economics (pp. 623-645). Amsterdam: North Holland.

Groeling, T. (2008). Who's the fairest of them all? An empirical test for partisan bias on abc, cbs, nbc, and fox news. Presidential Studies Quarterly, 38(4), 631-657.

Groseclose, T., \& Milyo, J. (2005). A measure of media bias. Quarterly Journal of Economics, 120(4), 1191-1237.

Gunther, A. C. (1992). Biased press or biased public? Attitudes toward media coverage toward media coverage of social groups. Public Opinion Quarterly, 56(2), 147-167.

Hallin, D. C., \& Mancini, P. (2004). Comparing media systems: Three models of media and politics. New York: Cambridge University Press.

Hanretty, C. (2010). Explaining the de facto independence of public broadcasters. British Journal of Political Science, 40(1), 75-89.

Incerti, T. (2020). Corruption information and vote share: A meta-analysis and lessons for experimental design. American Political Science Review, 114(3), 761-774.

Iyengar, S. (1991). Is anyone responsible? How television frames political issues. Chicago: University of Chicago Press. 
Iyengar, S., Curran, J., Lund, A. B., Salovaara-Moring, I., Hahn, K. S., \& Coen, S. (2010). Cross-national versus individual-level differences in political information: A media systems perspective. Journal of Elections, Public Opinion and Parties, 20(3), 291-309.

Iyengar, S., \& Hahn, K. S. (2009). Red media, blue media: Evidence of ideological selectivity in media use. Journal of Communication, 59(1), 19-39.

Kabashima, I., Takeshita, T., \& Serikawa, Y. (2010). Media and politics [Media to Seiji]. Tokyo: Yuhikaku.

Kane, J. V., \& Barabas, J. (2019). No harm in checking: Using factual manipulation checks to assess attentiveness in experiments. American Journal of Political Science, 63(1), 234-249.

Kaneko, T., Asano, T., \& Miwa, H. (2021). Estimating ideal points of newspapers from editorial texts. International Journal of Press/Politics, 26(3), 719-742.

Kobayashi, T., \& Yokoyama, T. (2018). Missing effect of party cues in japan: Evidence from a survey experiment. Japanese Journal of Political Science, 19(1), 61-79.

Krauss, E. S. (1998). Changing television news in Japan. Journal of Asian Studies, 57(3), 663-692.

Krauss, E. S. (2000). Broadcasting politics in Japan: NHK and television news. Ithaca: Cornell University Press.

Larcinese, V., Puglisi, R., \& Snyder, J. M. (2011). Partisan bias in economic news: Evidence on the agenda-setting behavior of U.S. newspapers. Journal of Public Economics, 95(9), 1178-1189.

Lazer, D. M. J., et al. (2018). The science of fake news. Science, 359(6380), 1094-1096.

Lee, T.-T. (2010). Why they don't trust the media: An examination of factors predicting trust. American Behavioral Scientist, 54(1), 8-21.

Levendusky, M. (2013a). Partisan media exposure and attitudes toward the opposition. Political Communication, 30(4), 565-581.

Levendusky, M. (2013b). Why do partisan media polarize viewers? American Journal of Political Science, 57(3), 611-623.

Lodge, M., \& Taber, C. S. (2000). Three steps toward a theory of motivated political reasoning. In A. Lupia, M. D. McCubbins, \& S. L. Popkin (Eds.), Elements of reason: Cognition, choice, and the bounds of rationality (pp. 183-213). Cambridge: Cambridge University Press.

Lodge, M., \& Taber, C. S. (2013). The rationalizing voter. Cambridge: Cambridge University Press.

Meijer, I. C. (2005). Impact or content? Ratings vs quality in public broadcasting. European Journal of Communication, 1(20), 27-53.

Nisbet, E. C., Cooper, K. E., \& Kelly Garrett, R. (2018). The Partisan brain: How dissonant science messages lead conservatives and liberals to (dis)trust science. The Annals of the American Academy of Political and Social Science, 658(1), 36-66.

Nyhan, B., \& Reifler, J. (2010). When corrections fail: The persistence of political misperceptions. Political Behavior, 32(2), 303-330.

Puglisi, R., \& Snyder, J. M., Jr. (2015). Empirical studies of media bias. In S. P. Anderson, J. Waldfogel, \& D. Strömberg (Eds.), Handbook of media economics (Vol. 1, pp. 648-667). Amsterdam: North Holland.

Soroka, S., Andrew, B., Aalberg, T., Iyengar, S., Curran, J., Coen, S., et al. (2013). Auntie knows best? Public broadcasters and current affairs knowledge. British Journal of Political Science, 43(4), 719-739.

Sugawara, T. (2016). Mass media survey not connecting society and politics [seiji to shakai wo tsunaganai mass media no seron chosa]. Studies of Broadcasting and Media, 13, 57-78.

Suzuki, T. (2015). Media control by ABE administration [Abe Seiken no Media Shihai]. Tokyo: East Press.

Taber, C. S., \& Lodge, M. (2006). Motivated skepticism in the evaluation of political beliefs. American Journal of Political Science, 50(3), 755-769.

Tandoc, E. C. J., \& Duffy, A. (2016). Keeping up with the audiences: Journalistic role expectations in Singapore. International Journal of Communication, 10, 3338-3358.

Taniguchi, M. (2015). Politics and mass media [Seiji to Masumedia]. Tokyo: Tokyo Daigaku Shuppankai. Taniguchi, M. (2018). Changing political communication in Japan. In F. Darling-Wolf (Ed.), Routledge handbook of Japanese media (pp. 121-135). New York: Routledge.

Turner, J. (2007). The messenger overwhelming the message: Ideological cues and perceptions of bias in television news. Political Behavior, 29(4), 441-464.

van Dalen, A. (2020). Journalism, trust, and credibility. In K. Wahl-Jorgensen \& T. Hanitzsch (Eds.), Handbook of journalism studies (pp. 356-371). New York: Routledge. 
Vosoughi, S., Roy, D., \& Aral, S. (2018). The spread of true and false news online. Science, 359(6380), 1146-1151.

Yamada, A., \& Kim, J. Y. (2016). Option-splitting effects in poll regarding Japan's right to exercise collective self-defense. Social Science Japan Journal, 19(1), 59-69.

Publisher's Note Springer Nature remains neutral with regard to jurisdictional claims in published maps and institutional affiliations. 